\title{
Pinguicula Elongata of Colombia
}

\section{J. Heberleyn HernandeZ-Melan • Bogotá • Colombia • heberhm@ hotmail.com}

Keywords: observations: Colombia, Pinguicula elongata.

I began to study carnivorous plants a few years ago after my botanist friend Randall Peterson gave me a book about carnivorous plants of the world. Ever since I finished my university studies, I have wanted to cultivate and learn more about carnivorous plants, but it is extremely difficult to find seeds or plants in our country.

After two years searching for carnivorous plants in the mountains near Bogotá, the capital of Colombia, with my friend Jairo Ramirez, I found some little red plants glistening in the sun growing on a mountain top.

We took some pictures of these red, healthy plants, some with two or three violet flowers. The plants were growing at an elevation of about $3000 \mathrm{~m}(9800 \mathrm{ft})$ in a little depression at the top of the mountain. They were very dispersed, but confined to an area of only about $60 \mathrm{~m}^{2}\left(645 \mathrm{ft}^{2}\right)$ growing with a variety of other plants like grass, frailejón (Espeletia brassicoidea, E. argentea), lupinius (Lupinus albus), romeros (Diplostephium rosmarinifolium), piñuelas (Aechmea spp.) and others typical of the Páramo, a neotropical high-elevation ecosystem (see Figure 1). The underlying geological formation is a rich sandstone called Formación Guadalupe. Because the area is a declivity, the ground is not waterlogged. The plants may get some water from the typical night fog.

From our photos, I made a drawing of the plant and sent it to Juerg Steiger in Bern, Switzerland. He identified the plant as Pinguicula elongata. I also sent some seeds for Juerg to germinate in his greenhouse, but none germinated, despite many attempts.

Pinguicula elongata grows in windy mountain regions that have specific seasonal characteristics. During the short summer season, from December to February, the Pinguicula rosettes are dormant, with only short leaves (see Figure 2). During this time, typical daytime temperatures are $28-30^{\circ} \mathrm{C}\left(82-86^{\circ} \mathrm{F}\right)$, and the nighttime temperature drops to $2^{\circ} \mathrm{C}\left(36^{\circ} \mathrm{F}\right)$. There is little or no rain during these summer months, but the nights are foggy. With the first rains in March, the plants revive and produce long leaves that are first pale green to lemon yellow (see Figure 3). In June, the plants change to a deep rusty reddish color (see Figure 4), and the plants produce their first flowers. The leaves and flowers give an incredible contrast with the green monotony of the Páramo. The growing season, March to August, is rainy and the nights are cold and foggy. Temperatures during this time are $5-10^{\circ} \mathrm{C}\left(41-50^{\circ} \mathrm{F}\right)$ during the day, and -2 to $+3^{\circ} \mathrm{C}\left(28-37^{\circ} \mathrm{F}\right)$ at night. During September through November the plants slow in growth and prepare for dormancy. Temperatures during this time are $8-15^{\circ} \mathrm{C}\left(46-59^{\circ} \mathrm{F}\right)$ during the day, and $0-5^{\circ} \mathrm{C}\left(32-41^{\circ} \mathrm{F}\right)$ at night, and rains are frequent.

The plants have two flowering seasons, the first is during the winter growing season in June to August, and the second is during November to January, as the plants enter their summer dormancy.

These Pinguicula plants are herbaceous perennials with a rosette at the base, elongated leaves with stalked and sessile glands covering the leaf surface. The leaves can grow to $15 \mathrm{~cm}$ (6 in), twisting as they ascend, and are covered by the insects caught by the mucilage. The root system is fibrous, but the roots are not long. The flowers grow from the center of the basal rosette. They are white to pale violet with five petals and a backwards pointing spur (see Figure 5). The stigma is white and the stamens are yellow. Each plant can produce three to five flowers. After pollination, the seed capsules turn from brown to black. When the seeds are ripe, the capsules dry and split in the sun, spreading the seeds. When the plants are dormant, they are strongly attached to the ground, and are difficult to find as they hide in the other vegetation.

Several months after our discovery, my son Sebastian found another small population of plants $85 \mathrm{~m}$ ( $280 \mathrm{ft})$ south, which we called zone no. 2. We have now found two additional areas, both within $200 \mathrm{~m}$ (660 ft) of the first two zones. We visit the four zones with my son almost every three months to see the plants, take pictures, and count the plants in the population. We have been spreading seeds to repopulate the Pinguicula because these mountains are very fragile. In 2003, a fire destroyed zone no. 1 and we were afraid that the population was lost. But, thanks to the natural seed bank, the population was not affected.

This carnivorous plant population is endemic to this area of the mountains. We have searched other areas having a similar ecosystem, but have found no additional populations. By our spreading seed, we believe we have increased the total population of Pinguicula in zones $1-4$ by about $40 \%$. We are convinced that this ecosystem needs to be protected and remain hidden from the people that want to reap it to sell these exotic plants.

Because the conditions are exacting and require a controlled environment, few people are capable of growing this kind of carnivorous plant in captivity. 


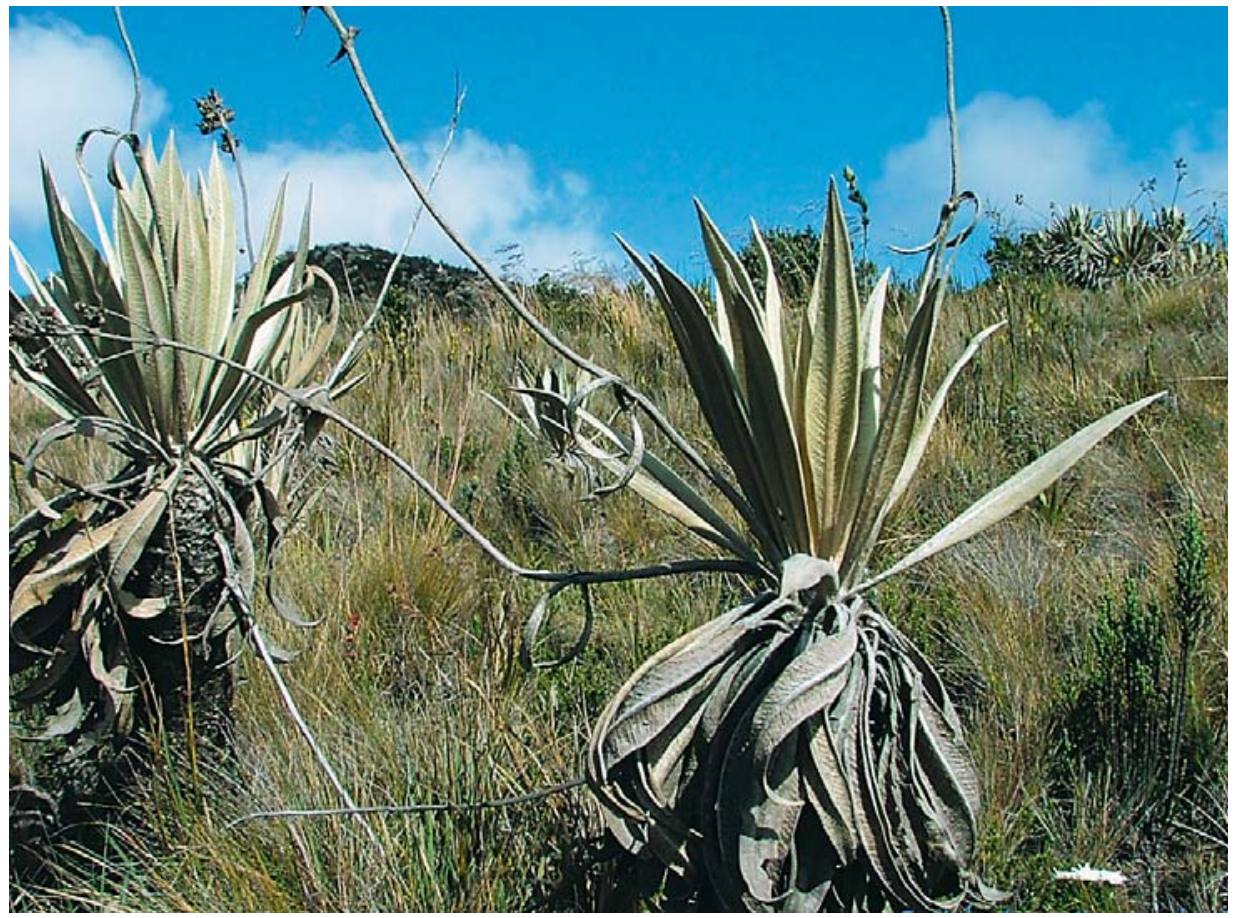

Figure 1: Páramo community; the large plants are Espeletia sp., in the Asteraceae. Photo by Heberleyn Hernandez-Melan.

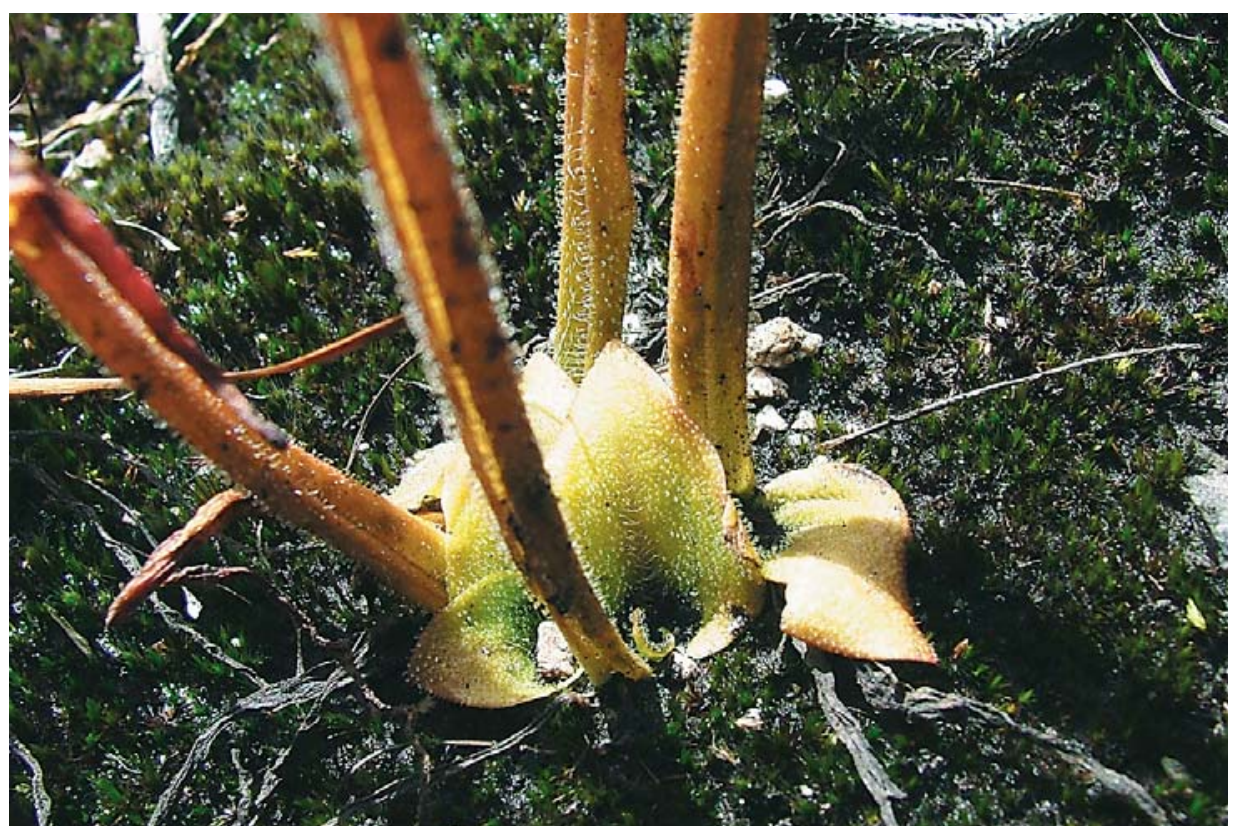

Figure 2: Pinguicula elongata in its short-leaved dormancy stage to survive the dry summer. Photo by Heberleyn Hernandez-Melan. 


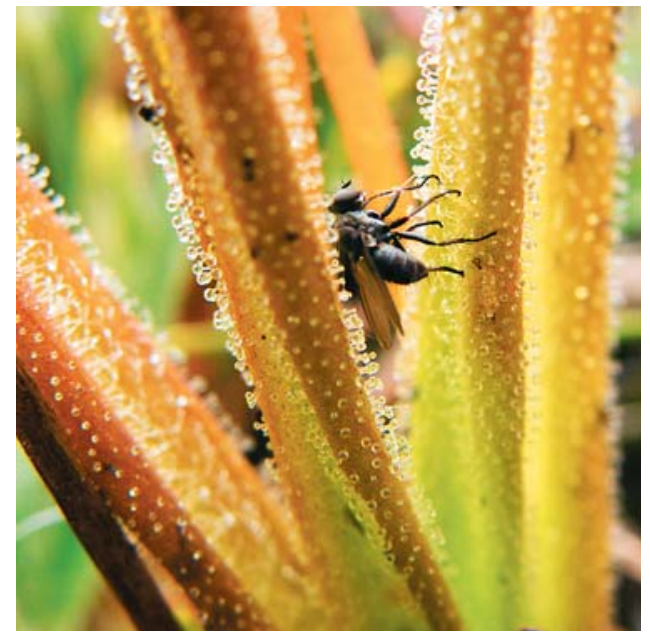

Figure 3:

A fly struggling on the leaf of Pinguicula elongata. Photo by Heberleyn Hernandez-Melan.
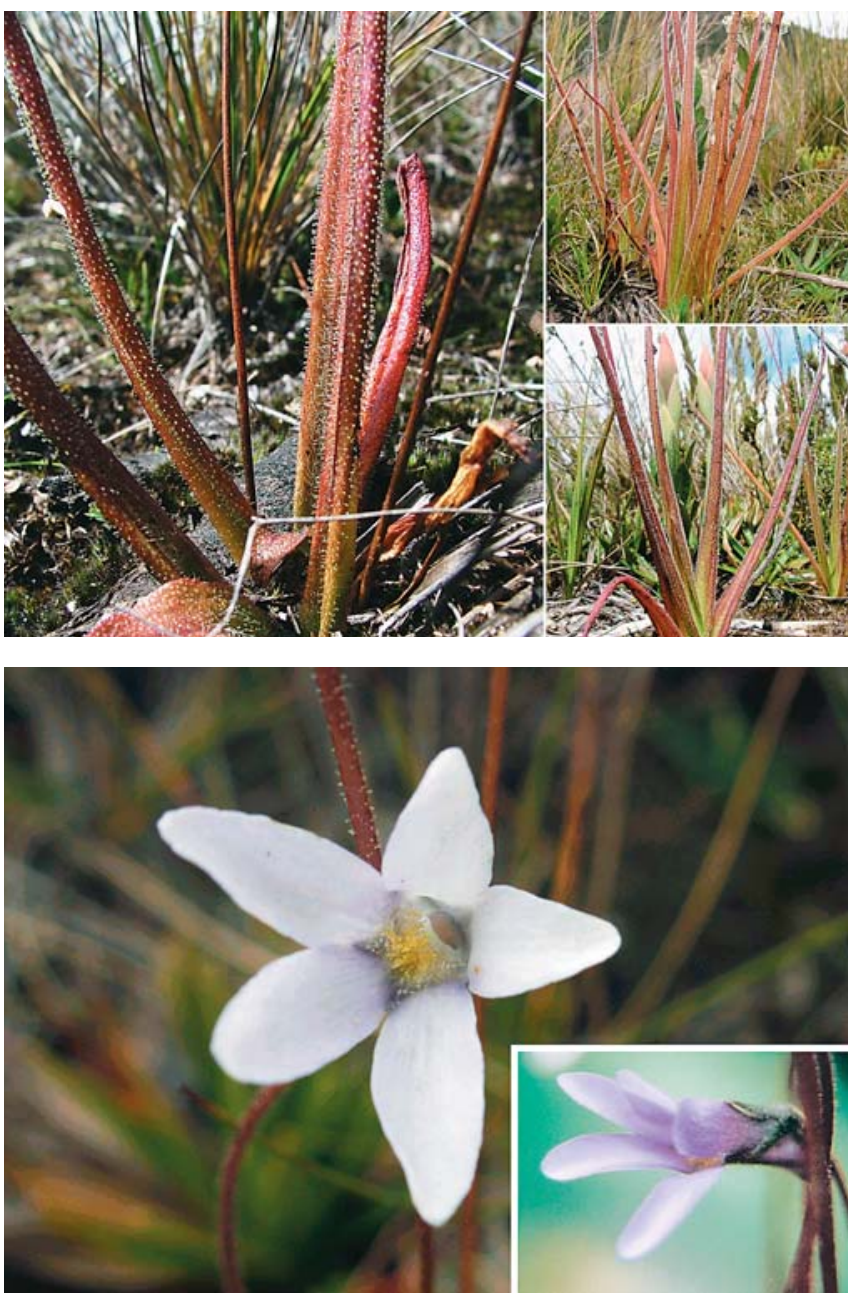

Figure 4:

Different Pinguicula elongata plants, showing a beautiful array of colors. Photo by Heberleyn HernandezMelan.

Figure 5:

A white Pinguicula elongata flower. The inset shows a more pink flower. The two photographs are not at the same scale. Photo by Heberleyn HernandezMelan. 